International Research Journal of Management, IT \& Social Sciences
Available online at https://sloap.org/journals/index.php/irjmis/
Vol. 7 No. 1, January 2020, pages: 95-103
ISSN: 2395-7492
https://doi.org/10.21744/irjmis.v7n1.826

\title{
From High-Performance Target to Social Destabilization: Analyzing Doping Drugs Overdose among Young Manual Workers in Northern Benin
}$$
\text { CrossMark }
$$

Abou-Bakari Imorou ${ }^{a}$
\end{abstract}

Article history:

Submitted: 27 November 2019

Revised: 09 December 2019

Accepted: 03 January 2020

\section{Keywords:}

doping drugs addiction; high-risk overdose;

Northern Benin;

performance quest;

social destabilization;

threshold shifts;

\begin{abstract}
This research work seeks to understand the mechanisms through which doping drug overdose gradually leads to social destabilization construct among young rural workers in Northern Benin. Regarded as high-risk behaviors spreading among the active youth, the inappropriate consumption of doping drugs turns out to become a source of public health problems among the majority of farming communities. The sociologically-oriented brainstorming sprouting from this research paper emerges as a result of an ethnographic study drawing on the qualitative research paradigm. It considers the risk perceptions issue in a social environment divided between the local social values conservation and hard work-driven productivity. The analyzed data are collected following long sequences of observations fitted in between by several individuals and focus groups interviews. The households are adopted to serve not only as observation units but also as spaces where the young over users of doping drugs socialize. Therefore, the young manual workers become bogged down in the new momentum giving rise to new social profiles the success of which depends on the overuse of performance-enhancing drugs. As a result of this practice emerge the overdose of doping drugs and other performance-enhancing medicines in view of meeting new workloads demands and exceeding one's natural social potential. This dynamic is captured here in the measurement of the changes and complexities it induces among the social groups on the one hand, and the threats it engenders to social reproduction in different localities, on the other. The analysis is carried out against the backdrop of the influence of social contexts and the social lines motivating doping drug overdose among the young manual workers.
\end{abstract}

International research journal of management, IT and social sciences (C) 2020. This is an open access article under the CC BY-NC-ND license (https://creativecommons.org/licenses/by-nc-nd/4.0/).

Corresponding author:

Abou-Bakari Imorou,

Associate Professor, Department of Sociology-Anthropology (DSA),

Université d'Abomey-Calavi (UAC),

Researcher at LASDEL Université de Parakou (UP), Benin.

Email address: aimorou@yahoo.fr

${ }^{a}$ Université d'Abomey-Calavi (UAC), Researcher at LASDEL Université de Parakou (UP), Benin 


\section{Introduction}

This research work is premised on discussing some social mechanisms surrounding the construct of social destabilization among the rural manual workers seeking high performance in agricultural production. This performance quest involves doping drug overdose. Those are pharmacological medicines and other chemicals consumed for performance-enhancing purposes. This subject gives room for a new understanding of the interest that the social sciences attach to those drugs. Indeed, the social sciences have raised some critical concerns regarding medicinal drugs due to a variety of problems related to their physical, financial and cultural access, their perception and nomenclature, the mechanisms of their use, their compliance or not with medical prescriptions, their social uses and the constructs that underlie them. Medicines occupy an increasingly important place in social life and thereby the importance the social sciences attach to them without pretending to adopt any biomedical posture.

The relationship to medicines in different social groups refers to a diversity of scientific concerns and interests. Each specific social field is therefore invited to the debate by emphasizing a very specific aspect. Economists have, over the years come up with the view that expenditures incurred on medicines have increased in recent years (WHO, 2011). From a public health point of view, the emphasis is put on the fact that medicine access ensures a better quality of care and has a good impact on life expectancy (Olivier de Sardan \& Ridde, 2014). Many research works conducted on the medicines have focused on concerns related to their accessibility (Richard, 2001; Doumbouya, 2008), compliance (Lamouroux, 2005). Similarly, drug misuse and overdose have since emerged as new research thematic in social sciences. Drugs are considered here in the dynamics of its consumption with the view to enhancing the users' performance; but also and above all, it's capacity to induce identity destabilization. Reflections are thus engaged following a dimension that mainstreams the forms of the medicalization of the social body. The interest in questioning the performative strategies of young people lies precisely in this last dimension.

Based on observations made in North Benin, an attempt is made to identify the dynamics linked to the diverted use of drugs for doping purposes among young people. While the adopted posture draws on the behavioral observation among the youth presented as the central actors of the above-described mechanisms, there still are some attempts to restore the influences of the social environment, the forms of socialization and the perceptions of socially valued figures in the constructs guiding their actions. Diverted drug consumption is here used for performance-enhancing or doping purposes and, therefore highlighting those doping drugs as pharmacological substances produced in industrial volume and marketed through the same channels as the medicines to which many of them are assimilated. The fact remains that they do not all belong to pharmacological classes, even though local popular discourses in many countries consider them to be drugs. If, on the whole, medicines are given certain popularity based on their biological efficacy and above all, on the capacity to heal (Desclaux \& Egrot, 2015), healing does not govern the effective use of drugs and "enhancers". Their uses are part of the diverted forms of drugs administration Milhet (2015), has attempted to define the phenomenon of diverted drugs use to indicate that it covers several dimensions: "the method for getting medicines, its destination, the intent behind its use, the way the medicine is administered and the route of administration". He considers that diversion occurs when these actions happen "outside the scope" (Milhet, 2015). Thus, from its procurement, dispensation, to consumption, there is the possibility of drug diversion. While in "Western countries medicines accompany a daily life, the duration of which they have helped to increase (Desclaux \& Egrot, 2015), in some localities their consumption causes serious public health problems. The emergence of the increasingly widespread use of performance-enhancing drugs nurtures the paradoxes serving as the backbone of the reflections underway in this paper. The problem is based on a mismatch between the beneficial role of medicines and the ravages of their circulation and their uncontrolled consumption or diverted use.

There are profusions of risks inherent with the diverted drug's consumption. In the existing literature, Milhet any has identified three motivations prompting young people to indulge in drug consumption outside any medical prescription: self-medication, partying, and academic or school success (Milhet, 2015). For those young people outside the school system, either graduates or drop-outs, such as those described in this text, the motivations are to improve individual performance in relation to the activities undertaken.

\section{Materials and Methods}

In order to meet up the objectives set for this research work, it has been absolutely necessary to follow the methodological approach that allows a qualitative mobilization of the materials and data gathered in the process. It is based on inductive approaches used in socio-anthropological studies. The discourses and behaviors analyzed are 
collected through life stories told by those young consumers of doping drugs. The criteria for mainstreaming (inclusion) or debarring (exclusion) of actors on the list of respondents are pertaining to the experience of meeting and using the concerned drugs. It is, therefore, a matter of studying the consumption behavior behind those drugs from the consumers' points of view and describing the practices underlying them. The approach is based on relative constructivism drawing on the theory of social configurations. This approach aims to understand the meaning that individuals give to their actions while integrating the social frameworks of behaviors. In implementing this approach, Weber (1947), invites us to understand the meaning of social action without locking ourselves into positivism.

The socio-anthropological approach (Olivier de Sardan, 1995), adopted in the context of this research gives significant importance to the actors' points of view and to the immediate and historical contexts of the observed behaviors. The consumption of performance-enhancing drugs. These are pharmacological substances or other chemical compounds or other infusions likely to increase the consumers' working capabilities (Imorou, 2019). The main interlocutors whose statements have been mobilized, collected and analyzed in this text are primarily young consumers identified by the snowball technique in the five (5) districts of the town of Malanville. The second category of actors is made up of witnesses and close relatives of young consumers.

The commune of Malanville was chosen for this analysis because it is presented to development agencies as a place where many risky behaviors are observed that jeopardize the development of children and young people. Thus, the consumption of doping products and other narcotics, force-feeding and child prostitution are identified as the daily lot of many young people. A total of 56 interviews were conducted with individuals who admit to using doping products, parents (fathers, mothers, guardians) of young people involved in agricultural activities, community leaders and local elected officials. The modes of access to products, socialization of their consumption, parental control, and social norms regulating young people's behavior are among the aspects documented in this research.

\section{Results and Discussions}

\subsection{An Ethnographic construal of the quest for performance}

The performative strategies discussed here consist of the diversion of drugs or other psychoactive substances used in order to increase the natural capacity of physical production generated for the consumer. Engaged in a productive process, the consumer uses these products to increase his or her capabilities and achieve performances that he or she could not have achieved naturally. The consumption of doping drugs can, therefore, be defined as a consciously constructed set of daily practices aimed at improving the physical or intellectual performance of actors through the "out-of-control" use of pharmaceutical drugs or other chemicals known for their ability to support the physical and intellectual effort of their users. These strategies are either individual or collective and more importantly, those drugs are swallowed or intaken without any prescription from the medical officers performing to deliver the sound "objectives of healthcare" (Milhet, 2015). The products (drugs, pharmacological products, etc.) taken as part of diverted consumption are not prescribed by health workers. Similarly, their supply channels are often not formal. They are in fact sold by street vendors or prostrate vendors in front of stalls selling various pharmaceutical products.

The drug's healing dimension and efficacy are not always the robust arguments raised and propounded by the sellers and adopted by the users. Moreover, those consumed drugs do not always range among the classic ones. They include other chemical compounds consumed due to their psychoactive or doping effects. These consumption strategies are developed by young farmers and other manual workers in order to increase their capacity and performance at work. Those drugs are used for various purposes and underscore different practices according to the sex of the users (female and male). For young boys engaged in farming activities, these practices help to improve their productivity, whereas for young girls it is much more a matter of overusing their bodies. Even though for the time being, there is no statistic figure on the phenomenon the observations made in the various localities of Malanville show that it is a very widespread practice. It is a phenomenon rampant among young adults as well as adolescents and even some children.

Among the young boys, the performative strategies have to do with agricultural productivity. And some adolescents seem to have been very quickly introduced to these practices during their socialization in the various farming fields. The doping medicines that lead to drug addiction are generally consumed by most young farmers and those engaged in those works which are regarded as necessitating and requiring extra energy. The most frequently cited of those medicines is Tramol. It seems to be consumed in all the districts of Malanville Local Government territory, and even beyond, in all the rice-producing and legumes gardening zones developed around the Niger River basin. Young active workers also refer to it as an effort generating and sustaining drugs in all the agricultural production zones of the six

Imorou, A.-B. (2020). From high performance target to social destabilization. International Research Journal of 
Local Governments of Alibori Region in Northern Benin. According to those young men and consumers of the drugs, it is preferably used due to its doping, stimulating and exciting effects at the same time. Those effects seem to be the major causes prompting exclusively young farmers and other manual workers, in general, to consume it the most. Here, the consumption of those drugs could be construed, from wome angle and point of view, as hard "pharmaceuticalisation" (Desclaux \& Egrot, 2015), of society, is taking place in a context of critical "trivialisation". Despite the Beninese government's fight against street drugs, there are still channels for the sale of these drugs in all of the above-mentioned communes.

"It is always the same vendors who continue to sell them. The difference is that this time it is not like any other time. They display all their articles except the medicines. And not everyone has access..." (S., Un relais communautaire de santé, Karimama, May 2016).

Experiences with the intake of the first drugs vary along the logic line substantiating their consumption. Some of those pharmaceutical products are discovered at the occasion of experiences of discomfort or temporary fatigue:

I came to the village for facilitating an event when I was affected by a high fever and a terrible headache. I was unable to get up talkless of moving around. I was lying in bed at the District Head's house. The District Head's wife gave F CFA 50 to her 5-year-old little girl to go and buy me some medicine. I did not know the name of the medicine but it only cost F CFA 50. After having swallowed it, I found myself and I normally went on my facilitation activity and I came back in great shape. That's how I got to know this Drug" ( K., Community Development Officer, Gogounou, July 2016).

Tramol and Tramadol are locally named according to logics that refer to their effects and assumed potency. Such denominations are inspired by the distinctive signs that appear on the product package. These signs can be related to the packaging as well as to the product itself. For example, Tramadol is referred to as "4 squares". This local name derives from the shape of the tablet divided into four parts on one side. Tramadol is also called Kymco, a name borrowed from a motorcycle of Asian origin, which is widely known for its top-level resistance, in particular on hard and hilly roads. The similarity in the shapes hard and hilly terrain is hereby dominated by the intake of Tramadol which henceforth makes everything possible. Some consumers call Tramadol "Bin Laden" or "Osama" to allude to the courage and strength attributed to that Islamist character. As one of the young men puts it: "You become as strong as Bin Laden when you take Tramadol". You become so strong that when you take Tramadol the physical task at hand is minimized.

Beyond strength, the viewpoint of the respondents and the popular mindset convey the idea that Tramadol or Tramol gives its consumers the desire, joy, and strength to work. When taken in high doses, Tramol or Tramadol tablets, according to those who talk to them, stimulate them and sometimes cause seizures similar to epileptic seizures. The tendency to gradually increase the dose consumed is systematic in all consumers. And it seems difficult for the consumer to set limits and respect them without any constraint.

The dosage increases as you consume it. When the product has finished its effect, the person concerned feels tired as if he has been working 24 hours a day without rest for a week and when he sleeps, he can be moved from one village to another without waking up. Consumption of Tramadol/Tramol makes one feel terribly thirsty". (O.M. a shop manager, Kandi, August 2017)

\subsection{History of drug consumption in the localities of farmers}

It is difficult to pinpoint the exact origin of drug use in the search area. However, it can be said with certainty that the practice is not new and that it is well known to the local population. The actors interviewed reveal that there have, for example, been actions to combat drug use since the revolutionary period during which local committees were set up

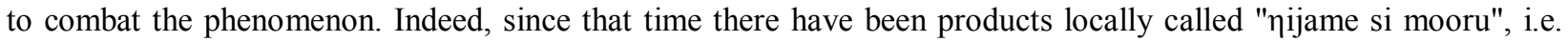
"Niamey is not far away" or "Baba Laakal", i.e. "Daddy, be careful!" to allude to the violence that consumers inflict on their parents who are committed to bringing them back to order. But the interlocutors also acknowledge that during this period, the phenomenon was not so widespread and that it only concerned a few marginal individuals who consumed the products in a very clandestine manner. The low social scale of observation of the phenomenon at that time is due to the measures taken during the revolutionary period to combat it. The result is the feeling that since the advent of democratic renewal, the fight against narcotic drugs has been abandoned and the phenomenon has become commonplace and widespread. 
It must be recognized that the phenomenon of diverted consumption of medicines and narcotic drugs, in general, has an exogenous origin in the social circles concerned here. Indeed, it was previously practiced by foreign agricultural workers who came from the countries of the subregion in search of paid work. Although these workers were employed in agriculture, some of them worked in the loading and unloading of trucks. They consumed a number of products estimated to give them energy and endurance to endure the hardship of the work. Others also took other products as a pick-me-up after a hard day's work. Over time and by contagion, the strategies of these non-native people began to spread throughout the region. Thus, young natives would also have started to consume the same products.

Thus, initially, the consumption of the "increments" was essentially in line with the objective of good performance at work. It simply appeared as a solution to cope with overwork. It allows going beyond one's real physical capacities. Even today, the consumption of drugs seems to be underpinned by the same objective. For Tramol addicts, it is almost impossible to do fieldwork and other hard work without the help of Tramol. The use of Tramol for fieldwork is considered to be a well-known and accepted practice and young people to increase their yield. Its consumption in the fields and other places of hard work has become a local "practical norm" (Olivier de Sardan, 2017) in the productive process in all localities in these areas of high agricultural production. Practical norms are conceived by Olivier de Sardan (Op.cit) as forms of factual regulation that underlie the practices of actors who deviate from formal norms. Tramol is thus present even during collective activities. Similarly, it is part of the maneuver kit when its services are used.

We are increasingly witnessing important forms of deviance in the consumption of these products because of the monetary value of work, the importance of money in social relations, the way family resources are managed, which is questioned by young people facing other social constraints, etc. The development of economic activities in some towns such as Malanville, the emergence of new lifestyles essentially based on the monetization of social relations and life in general, the emergence of new social problems, and the geographical position of certain communes with porous borders through which all kinds of prohibited goods pass, all contribute to facilitating and maintaining this behavioral deviation.

In addition to this, new agricultural incentive policies encourage peasants to engage in mass production, while at the same time leading them to surpass themselves in their work. Within the framework of policies promoting the various agricultural sectors, particularly cotton and food products, young people and adolescents benefit from numerous accompanying measures issued by the government. In order to take advantage of these measures, to make the investments made by the Government profitable, to find the resources to pay the credits contracted, and also to honor the commitments, young people and adolescents are obliged to work beyond their physical limits. This requires the use of narcotics to get high. In this environment, Tramadol and products of the same pharmaceutical class are thus the first recourse. They are seen as providing additional energy to better cope with the challenges facing young people. All the young people we met agreed that Tramadol-based products are likely to give their consumers the courage and the will to take action that would not be possible under normal conditions.

\subsection{Factors fostering the persistence and maintenance of high risk behaviours}

There are a number of factors that encourage the observation of these risk practices and behaviors to which young subjects are exposed. These include the availability of the products used, the commodification of youth work and labor, the monetization of agriculture, whose various sectors are being transformed into a cash crop sector by government incentive policies in the agricultural sector, the high value of money in social relations, the poor management of family resources by the elderly to the detriment of young people, the personal success projects of adolescents, who demonstrate the need to build their lives "by the sweat of their brow", etc. The social organization also largely supports the arguments for observing these phenomena of using "augmentation".

In his effort to develop a structuring theory (Giddens, 1987), proceeds to double destruction: that of the imperialism of the individual subject and that of the imperialism of the societal object. The theoretical bias in this text is therefore in line with this perspective, which values social practices noted in space-time and not "the experience of the individual actor or the existence of social totalities" (Idem). We, therefore, attempt to grasp here the context of the emergence of the diverted use of drugs by ensuring the overcoming of individualistic postures that are limited to the rationality of the actors and the rationality of postures valuing the dictates of the societal. If it is true that young people are agents who adopt behaviors with precise goals, it is appropriate here to relativize the influence of these goals, which confine the analyses to a kind of voluntary rationality. These goals are sometimes the result of a construct linked to socialization and their analysis requires taking into account the structural context.

Imorou, A.-B. (2020). From high performance target to social destabilization. International Research Journal of 


\subsection{Threshold shifts and the social production of stigmatization}

The diversion of drugs for the purpose of doping puts the person taking them into a process of self-management of his or her trajectory. With the initiation rites that take place with the first doses, the consumer is gradually freed from the recommendations of the initiator. Although in some cases the methods of obtaining drugs are linked to control and therefore to the management of consumption trajectories, there is a tendency to note forms of the emancipation of individuals in their relationship with their product. Thus, the frequency of drug use and the way in which it is consumed are progressively locked into the singular colloquium of the consumer to himself. Several social registers can be noted which determine the relationship to the consumption of "enhancers".

First of all, there is a record of formal prohibition. At this level, the family does not expect the subject to go beyond his real capacities. The subject is not always laborious but his production is limited to his own natural capacities. In this register, parents do not ask themselves whether their children are in an environment where they can come into contact with the products or not. The discourse is firm and refers to a systematic rejection of the use of these products, including with religious arguments. There is also the register of awareness of the access to the Augments. At this level, parents deal with the awareness that their children may come into real contact with the products or will hear about them. In this case, the speeches made towards children are likely to condemn their consumption. Elements linked to the harmful and devaluing nature of products are mobilized to ensure controlled access. Under these conditions, we find ourselves within the limits of the initial threshold where the problem is not access to the product but its consumption. The discourse heard in these cases is such as to recognize the high probability of young people coming into contact while insisting on a formal prohibition on their use. In addition, there is the register of awareness of the productive interest of the "increaseers". The Thresholds defined by the self-control groups. Parents are not involved in the control of consumption.

Young people today don't know how to make the right choice, in our time there were no drugs to take to work. But today, there is not a single job that you are going to ask young people to do for you and they are not going to ask you for the medicine money. Even if it's a paid job, the medicine money is separate. And that's common knowledge. They say it's against fatigue" (D., Notable. Guéné, Sept 2017).

There is also the register of the awareness of the effectiveness of the consumption of incremental stamina to support the effort. At this level, consumption is accepted and the individual is more or less invited to determine a personal threshold to support the physical effort necessary to achieve the production objectives.

We have no other activities here apart from work in the fields. And to do the fields, we don't have any machines or tractors. The oxen do the ploughing and everything else is done by hand. In your opinion, how can we get by without these products that give us more strength? These products don't do anything wrong, they help us improve our performance in the field. Anyway, I'm taking some (Statement by S.A, a young producer. Madékali, Sept 2017)

Finally, there is the register of awareness of the incapacity to not consume. Here appears the jousting consumption. The individual falls into addiction and cannot consume. Consumption, in this case, does not necessarily lead to production.

"On the other hand, there are others who cannot do anything at all without Tramol, even walking. They are not able to walk if they have not taken Tramol, otherwise, they crawl ... they can't do anything at all, it's a danger ..., (Comments by S.D., Community Relay, Toumboutou, Jul. 2017).

It appears that the social destabilization into which some young Tramadol users fall is the result of a long process. The family norms that are supposed to indicate the conduct to be followed by young producers are constantly being negotiated. These norms seem to be doomed to different fortunes depending on the family. If in all families the first attitude is one of prohibition, there are somewhere social control prevents the individual from falling into the consumption of his products. On the other hand, in others, the norms that prohibit become loose when confronted with the hold of the local social environment on young people. Thus there are processes of gradual shifts that can be observed and the slider of prohibition is constantly shifted. Without abandoning the norm of prohibition, consumption becomes tolerated when it aims to support the effort. What is condemned by all is that which is in keeping with the consumer individual's need for enjoyment. 


\subsection{Analytical matrix of consumption thresholds}

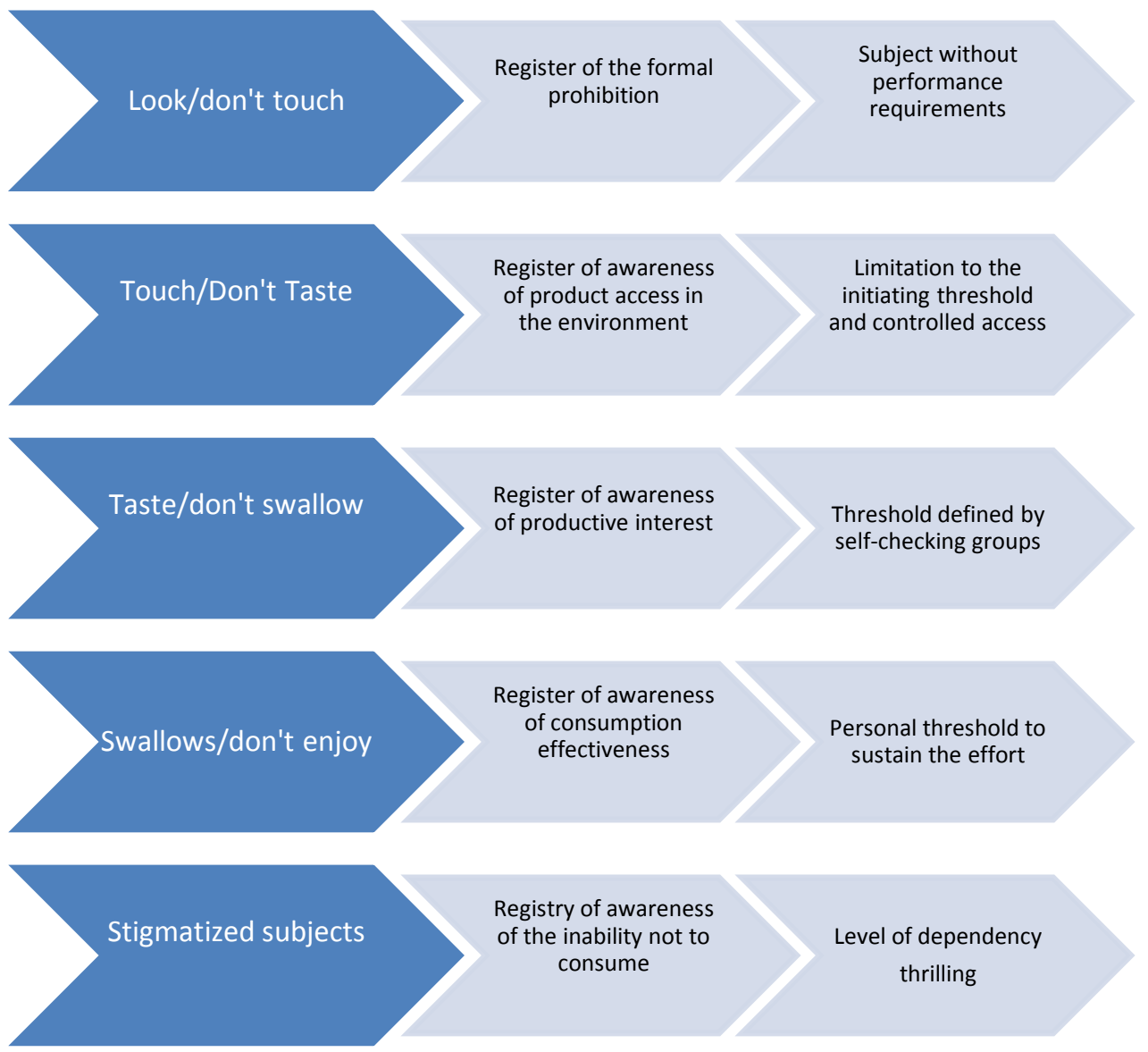

In the analysis, one can distinguish between pure non-addicts, transient consumers to addicts, pure addicts and consumers coming out of addiction. All of these categories create a complex field of observation of addiction in relation to local social perceptions. Pure non-addicts are those who do not use any doping product to perform their daily tasks. Here we find young people who are subject to rigorous social control against a background of religiosity. These are also young people who are not strongly committed to early financial empowerment. Even if they do make use of these products, they move away from them very quickly before their neighbors even realize it. Their social environment is not conducive to the use of these products.

You can't consume these products here. All the parents will insult you so much that you will even want to disappear. It's very frowned upon and the old man will say that you've shamed him by consuming this. It's like drinking alcohol. There are some concessions that you will never take the girl in marriage because people will say that you will become a drug addict and abandon their child. (L.O. Motorcycle parts seller, Guéné, April 2017).

Consumers in the transition to dependence are in a context of social acceptability of the use of doping products to support the production effort. They seem to be the most numerous and consume these products only to go to work. As a village producer group leader points out:

There are some working people who consume these products only to go to work. And when they take the tablets they really work hard. When they don't have the pressure of work, they don't take them at all. Once they have earned some money, they go home and can go days without going to work and therefore without consuming. It is often laborers who work in other people's fields to earn money, and very often these are young migrants who have no

Imorou, A.-B. (2020). From high performance target to social destabilization. International Research Journal of Management, IT and Social Sciences, 7(1), 95-103. https://doi.org/10.21744/irjmis.v7n1.826) 
fields for themselves and live solely on the fruits of their labouring efforts. (S., community relay, Malanville, June 2017).

Pure addicts are consumers who are engaged in the addiction trap. It is a lasting and stigmatized addiction. They are referred to as "drug addicts" even if they do not use drugs (hard drugs such as cocaine, heroin and indian hamps) in the real sense of the term. They are those who, according to popular opinion relayed by one person:

...they can't do anything at all without Tramol, even walking. They are not able to walk if they have not taken Tramol, otherwise, they crawl ... they can't do anything at all, it's a danger (S., community relay, Malanville, June 2017).

Consumers coming out of addiction are consumers who have personally experienced pure addiction but who are engaged in a dynamic of social recovery. Here, real social control is established in order to rescue the social identity of the individual who was once a worker but has just overnight fallen into the stigma. Several resources are mobilized to ensure the transition to non-addiction. They also reflect the fact that addicted consumption of these drugs is experienced as pathology by some relatives. The consumer, therefore, becomes a sick person who needs to be cured.

\section{Conclusion}

The observations made on the issue of the overuse or overdose of doping drugs point to an ambivalent social environment that is part of the valuation of labor but can proceed to lead to a social destabilization as soon as the individual falls into addiction. He or she gradually becomes a "drug addict". This status often results from the search for the effectiveness of products, which involves a gradual increase in daily doses. The search for performance at all costs generates adverse and undesired effects that result in poor management of consumption thresholds useful for the needs of the cause. This mismanagement transforms the young consumer from a brave and respected young farmer to a marginalized and stigmatized subject. This is the core of the dynamics of the collective construction of social marginalization. Taking into account the context of production of this marginalization gives room to understand the role that the social environment plays in the slide of young people into joyful consumption. Strauss has already identified this need to add action to the context or social environment in which it is carried out (Strauss, 1992). This is an analytical approach that, while based on the individual actor and his actions, gives pride to the social processes in which he is engaged, the structural frameworks that condition his actions and give them meaning.

Therefore, access to drugs does not go through any formal control of their quality or medical relevance. This develops far away from the distribution channels governed by the pharmaceutical monopoly whereby someone is there, responsible for ascertaining the effects and detect the poor quality of the drugs consumed. The informal nature of distribution channels is largely a cause of this state of affairs.

\section{Conflict of interest statement}

The author hereby declares that she has no competing interests.

Statement of authorship

The author has a responsibility for the conception and design of the study. The author has approved the final article.

Acknowledgments

I am grateful to two anonymous reviewers for their valuable comments on the earlier version of this paper. 


\section{References}

De Sardan, J. P. O. (1995). Anthropologie et développement: essai en socio-anthropologie du changement social. KARTHALA Editions.

De Sardan, J. P. O. (2017). Rivalries of proximity beyond the household in Niger: political elites and the baab-izey pattern. Africa, 87(1), 120-136. https://doi.org/10.1017/S0001972016000723

Desclaux, A., \& Egrot, M. (2015). Anthropologie du médicament au Sud: la pharmaceuticalisation à ses marges. L'Harmattan \& Éditions de l'IRD, Collection Anthropologies et Médecines.

Doumbouya, M. L. (2008). Accessibilité des services de santé en Afrique de l'Ouest: le cas de la Guinée.

Giddens, A. (1987). La constitution de la société, Paris, PUF. Sociologies.

Imorou, A.-B. (2019). Social Production and Drugs Addiction Management among the Young Manual Workers in Northern Benin. International Journal of Research in Sociology and Anthropology (IJRSA), Volume 5, pp. 1-12.

Lamouroux, A. (2005). Compliance, observa,nce ou adhésion thérapeutique: de quoi parlons-nous?. Revue des Maladies Respiratoires, $22\left(\mathrm{n}^{\circ} 1\right)$, pp. 31-34.

Milhet, M. (2015). Usages détournés de médicaments psychotropes par les adolescents et jeunes adultes. Revue de littérature. Saint-Denis, OFDT.

Olivier de Sardan, J. P., \& Ridde, V. (2014). Une politique publique de santé et ses contradictions: la gratuité des soins au Burkina Faso, au Mali et au Niger.

Richard, J. L. (2001). Accès et recours aux soins de santé dans la sous-préfecture de Ouessè (Bénin) (Doctoral dissertation, Université de Neuchâtel).

Strauss, A. (1992). La trame de la négociation. Sociologie qualitative et interactionnisme, 10(4), 154-157.

Weber, M. (1947). The theory of economic and social organization. Trans. AM Henderson and Talcott Parsons. New York: Oxford University Press.

Imorou, A.-B. (2020). From high performance target to social destabilization. International Research Journal of 